
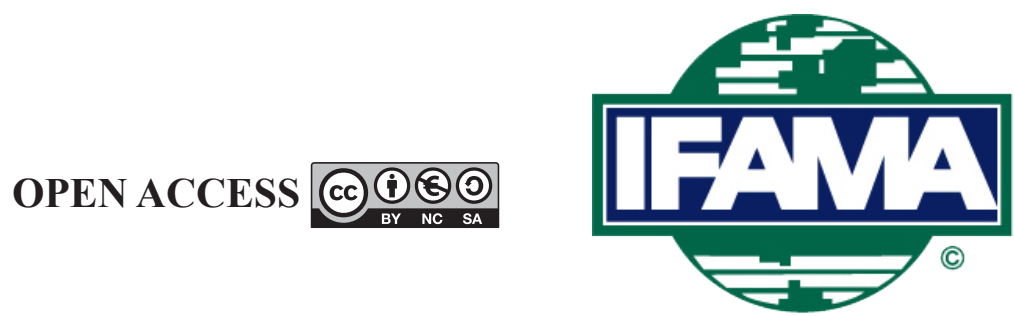

International Food and Agribusiness Management Review

Volume 23, Issue 4, 2020; DOI: 10.22434/IFAMR2019.0119

Received: 29 July 2019 / Accepted: 6 June 2020

\title{
Forging researchers-farmers partnership in public social innovation: a case study of Malaysia's agro-based public research institution RESEARCH ARTICLE
}

\author{
Nur Hanis Mohamad Noor ${ }^{\mathrm{a}}$, Boon-Kwee $\mathrm{Ng}^{\circledR b}$ and Mohd Johaary Abdul Hamid ${ }^{\mathrm{c}}$ \\ ${ }^{a}$ Graduate Research Assistant, ${ }^{b}$ Senior Lecturer, Department of Science and Technology \\ Studies, Faculty of Science, University of Malaya, 50603 Kuala Lumpur, Malaysia \\ ${ }^{c}$ Deputy Director, Quality Management Programme, Corporate \& Quality Communication Center, \\ Malaysian Agricultural Research and Development Institute, 43400 Serdang, Selangor, Malaysia
}

\begin{abstract}
This paper explores the effective roles of public research institutions (PRIs) in social innovation and understand the element of communal support in researchers-farmers partnership. The case study on Malaysian Agricultural Research and Development Institute (MARDI) reveals that the partnership between researchers and farmers is limited. The only productive and formal channel for researchers to reach the farmers is through agricultural extension agencies. It found that there are three elements that drive sustainable social innovation in agriculture: (1) quality research by PRIs; (2) efficient extension agency in disseminating knowledge to farmers; and (3) productive farmers in delivering high-yields farming. This paper claimed that the presence of partnership between researchers in PRIs and farmers is the crucial pivot in ensuring innovation reaches the target group. The study also found the potential of civil society organizations to transform farmers into more active innovation actors in the agricultural innovation system.
\end{abstract}

Keywords: agricultural extension services, sustainable agriculture, public innovation, MARDI JEL code: O21, O35, Q18

\footnotetext{
(i)Corresponding author: bkng@um.edu.my
} 


\section{Introduction}

Malaysian rice farmers are still vulnerable and highly depending on government assistance such as subsidies on fertilizer, pesticide and other welfare assistance (Ministry of agriculture and agro-based industry Malaysia, 2011). They are the groups that will be affected the most when it comes to economic crisis. In fact, besides the nation's need for more farmers to accommodate the demand for its main staple diet, the dependency on imported rice, inefficiency in its rice production and low generated income for farmers caused the nation billions of dollars to invest in incentives and subsidies just to ensure all Malaysians have enough rice on their plates (Rosnani Harun et al., 2016). In the context of sustainable agriculture, agro-based public research institutes (PRIs) act as agricultural extension services to the farmers in providing advice, information and other support services to farmers to enable them to improve their productivity and income. They are also key players in executing governments' rural development policies and programs through the execution of public social innovation (Adebayo et al., 2015).

Public innovation aims to deliver new ideas and concepts, technologies, techniques and methods, forms, systems and procedures to form meaningful interactions between public entities and society to address societal challenges (Bekkers et al., 2011: 6). In fact, a good governance is characterized as successful partnerships between public entities and the citizens, or public participation (O’Byrne et al., 2014). Nonetheless, existing studies on public innovation tend to focus on the administrative efficiency of government machineries in outsourcing, privatization and procurement (e.g. Baxter et al., 2010; Lember et al., 2011) and in agricultural sector which is mostly about firms' capability-building through catching-up strategies (e.g. Iizuka and Gebreeyesus, 2018; Thutupalli and Iizuka, 2016; Wong and Lim, 2019). The role of public (or governmentled) innovation in tackling the actual emerging social challenges of communities (or public social innovation), particularly amongst the individual farmers and villagers is somehow not clearly articulated in the literature.

Based on this background and a case study on an agro-based PRI in Malaysia, this paper examines the roles, issues and policy setting of public social innovation in the context of agricultural innovation system in developing countries. In general, PRIs is defined as 'public and semi-public research institutions (excluding pure university institutes), regardless of their statistically-defined sector (government, higher education, business or private non-profit)'(OECD, 2011: 27). The focus of the paper is guided by the main research questions to address the effective roles and mechanisms of agro-based PRIs in fostering and sustaining the social relations between researchers and farmers. We examine how researchers-farmers partnership leads to the increase of learning and skill development of farmers (as end-users as well as community) that eventually contributes to successful public social innovation.

This paper contributes in two major ideas. Firstly, it fills the literature gap in researchers-farmers partnership especially in humanizing public institutions and promoting a relatively more dynamic social innovation initiative. Notably, farmers play roles in innovation projects but we know little about how they best play their part for research and extension outcomes (Crawford et al., 2007). Hence, this paper addresses the communication network in the process of scientific and technology transfer of the researchers-farmers' partnership. In this context, social innovation not only satisfies unmet human needs but also demands transformation of social relations including governance system and organization (Moulaert, 2016). Secondly, it suggests broad policy directions in strengthening the roles of PRIs in delivering public social innovation. Although PRIs are vital for the government to implement policy and regulation, studies on the institutions are still limited, especially when it comes to the context of social innovation. A better understanding on PRIs is needed as the literatures regarding the functions of PRIs are heterogeneous and there is no consensus on how PRIs should behave (Lauritzen, 2017; Mazzoleni and Nelson, 2007; Ngongoni et al., 2017). For this reason, the vast experiences of Malaysian Agricultural Research and Development Institute (MARDI), the main PRI in rice variety research in Malaysia, serves as a strong and informative source of empirical evidence for this paper. 
The article is organized in six sections. Section 2 provides the theoretical basis and research framework of this paper. Section 3 explains the research method used in obtaining the empirical evidence to address the main research questions. Section 4 presents the main findings. This is followed by discussion and salient broad policy directions in Section 5. This paper ends with a short conclusion.

\section{Conceptual basis}

\subsection{Community and public research institution in social innovation}

Social innovation positions societal benefits before individual interests and this unique feature differs it from business innovation that prioritizes profit maximization and technological advancement (Mulgan et al., 2007; Phills et al., 2008). In other words, social innovation focuses on community (and societal) development in terms of income, infrastructure, capabilities, knowledge, skills, networking and institutions (Julie CaulierGrice et al., 2012). Moreover, case studies on developing economies showed that community is the backbone of public-driven sector in agriculture industry (Short and Kopp, 2005; Wu, 1995). The partnership between community as the consumer and industry player as the producer is close and both parties utilize their social capital and mutual understanding to develop the technological capabilities of the industry. The community is not only functioning as consumers, but their active involvement and feedback act as a catalyst to technology transfer and innovation diffusion. Thus, end users (such as farmers) in developing countries could no longer be presumed as inactive and incapable innovation actors, but their contribution could be a significant denominator for successful social innovation (Beza et al., 2017).

In agricultural sector, there are two essential roles of PRIs to support community in social innovation. The first is knowledge creation. As knowledge is a source of future sustained growth that is non-excludable and non-rivalrous in its application, this makes PRIs (with a pool of scientists and researchers) a crucial actor to increase the nation's productivity, economic growth and employment (Yang and Jung, 2016). Secondly, PRIs act as agriculture extension services to the farmers in providing advice, information and other support services to farmers to enable them to improve their productivity and income. They are key players in executing government's rural development policies and programs (Bekkers et al., 2011). Their roles as agriculture extension agencies are indeed in parallel to the concept of innovation intermediary in delivering social innovation in the setting of researchers-farmers partnership.

\subsection{Researchers-farmers partnership: mechanisms and communication network}

In agriculture, terminologies such as participatory design approach, collaborative design, co-design and co-innovate are used to describe the researchers-farmers partnership (Berthet et al., 2018). The concept of partnership suggests that the shared interests are usually exhibited through a common goal. The mutual benefits are obtained by exploiting shared interests and differences among the partners who bring along different strengths and resources to the alliance (Denning and Bernardo, 1995). In researchers-farmers partnership, the community attempts to understand a particular issue where they have to engage with others from similar backgrounds (usually farmers with farmers) and those with quite different knowledge and experience (usually farmers with researchers, or farmers with advisors). This diversity of knowledge creates a rich information environment and fosters a series of communication cycles to develop a new understanding of the issues (Crawford et al., 2007). This form of research co-production approach recognizes and optimizes the attributes of researchers and farmers, that is, researchers deliver scientific knowledge and experience; farmers contribute indigenous knowledge and experience, as well as feedback on technology performance (Denning and Bernardo, 1995: 376).

In our effort to examine the impact of PRIs on researchers-farmers partnership in the agricultural sector in developing countries, we are informed that the systematic involvement of farmers as users of agricultural technologies in most PRIs has been weak (with the exception in commercial, large-scale and producers of high valued export crops). There are two reasons for the lack of farmers' (as users) influence on public 
sector research: (a) lack of internal motivation in PRIs to be responsive to users particularly those that are politically marginal; and (b) lack of external pressure as resource-poor farmers are usually not sufficiently well organized to exert pressure (Merrill-Sands and Collion, 1994). Hence, scholars suggest the researchersfarmers partnership can be fostered and strengthened via the introduction of participatory research approach - a continuum approach based on the principle of researcher-led (farmers as contractors) to collaborative settings that emphasizes client-driven (farmer-led) (Snapp et al., 2002: 413). This approach can be executed in the field through 'mother-and-baby' trials. This mechanism collects data from mother trials managed by researchers and the data is systematically cross-checked with the baby trials on a similar theme that are managed by farmers. The 'mother' trial is simulated within-site (either on-research station or on-farm) to experiment a range of research with the close monitoring of researchers. The 'baby' trial comprises several satellite trials under farmer's management. (Snapp, 2002). In this context of communication network, PRIs has the potential roles to play as innovation intermediary, that is, an organization or body that acts as an agent or broker in any aspect of the innovation process between two or more parties' (Howells, 2006: 720). The roles of innovation intermediaries provide a good understanding of how PRIs could function in technology diffusion and transfer, innovation management, systems and networks, and as service organizations (BoonKwee et al., 2016; Howells, 2006).

\subsection{Roles of government}

The framework of National Innovation Systems recognizes PRIs as a non-market actor and they form a nonbusiness network with other actors in the nation (Lundvall, 1992). Thus, policy to strengthen the roles of PRIs in researchers-farmers partnership for social innovation should go beyond just fixing market failures. In fact, policymakers should identify and develop interventions to fix the weaknesses in the systemic failure such as the way the various agents interact with each other and with non-market institutions to enhance technological learning and structural transformation (Iizuka and Gebreeyesus, 2018). Nonetheless, it is a great challenge for policymakers to design strategies to increase the participation of PRIs in this partnership as the process of knowledge creation and dissemination is becoming increasingly collaborative. The success of innovation is thus determined by the right configuration of global scientific knowledge and local agroecological knowledge (Thutupalli and Iizuka, 2016: 5). In this regard, government is expected to the following interventions to initiate, support and facilitate the following functions (Iizuka and Gebreeyesus, 2018: 62): knowledge development and diffusion; entrepreneurial experimentation; market formation; guiding the direction of search; legitimatization; resource mobilization; and development of positive externalities.

Meanwhile, a report by United Nation Development Program (UNDP) on social innovation for public service excellence has concluded six main reasons for government (and PRIs in this context) to perform social innovation. This includes to, among others, improve outcomes by harnessing the power of a diverse range of social innovators and communities; enhance implementation at scale by offering lessons and approaches gained from the power of co-developing solution; build on existing community assets and capabilities; and improve public institutions by the greater involvement of citizens as partners of the state (UNDP, 2014: 3 ). The interventions of government have witnessed an encouraging outcome. The experience of Taiwan Agricultural Research Institute (TARI) has shown PRIs are effective in the capability-building process that encourages productivity and innovation, particularly in agricultural sub-sectors that rooted in a Marshallian network. The case of TARI shows that strong interaction between scientists is enabling farmers to adopt increasingly complex technologies. As a result, farmers are equipped with both productive (to increase yield) and innovative (to adapt to new knowledge and skills) capabilities (Wong and Lim, 2019). Nonetheless, policymakers need to be caution in adopting the lessons learned in the literature as these case studies are mainly focusing on non-traditional agricultural export products (e.g. fruits and vegetables) or cash crop, or farmers in firms setting (to discourse on firm catch-up and market formation). To a certain extent, those case studies are different from the context of the case study in this paper, i.e. individual farmers (mostly villagers) within a rice (as staple crop) industry which is highly regulated in terms of its research and market structure by the government. We will discuss these differences in Section 5 of this paper. 


\subsection{Conceptual framework}

Figure 1 illustrates the conceptual framework based on the conceptual basis discussed above. In general, government determines its social objectives in the attempt to achieve social innovation agenda and such national effort is closely guided and facilitated by targeted policy directions and instruments. In the agricultural sector, government gives mandates and allocated appropriate resources to PRIs to perform the determined social innovation agenda. PRIs are expected to perform the roles of knowledge creation and diffusion, and this is underpinned by the researchers-farmers partnership. This is in line with the social objectives of government in executing the social mechanism that value the participation of rural community (i.e. farmers) in capacity building process. Indeed, social mechanism is needed to empower people to make changes happen (Bock, 2012). As a result, farmers are equipped with both productive and innovative capabilities that lead to social transformation, that is, changing (rural) society (Moulaert, 2016; Mulgan et al., 2007). The social mechanisms could be observed through the synergy of researchers-farmers partnership that representing PRIs as science-based knowledge creator, and farmers as end-user of scientific knowledge. This co-creation model gives more autonomy to the non-scientific community to innovate (McKelvey and Zaring, 2018). The underlying principle of this framework is the researchers-farmers' partnership is communally supportive and aims to transform the society. The farmers act as active players in the industry and no longer as passive recipient (Beza et al., 2017; Mumford, 2002).

\section{Research method}

\subsection{Scope and context of the study}

This study is about the effectiveness of researchers-farmers partnership for social innovation based on the case study on an agro-based PRI in Malaysia's rice industry. The farmers engaged in this study are individual farmers (mostly villagers). The selection of rice industry as the case study is also because rice industry is staple food for Malaysia and this provides an excellent platform for us to observe and examine the impact of PRI on social innovation among the community (i.e. farmers). While we aware that the value chain of rice industry is extensive and complicated, this study mainly focusses on the rice-paddy variety R\&D because this is the segment that involves most of the researchers (and scientists). For this purpose, MARDI which is the only PRI in Malaysia's rice-paddy variety R\&D is used as a case study.

There are two aspects that the case has been examined: end user's participation in rice varietal development, and transfer of knowledge for both scientific and know-how between researchers and farmers. There are questions that we try to answer by using the framework - how do farmers and researchers engage with each other during rice varietal development process? Are farmers acting as active participants in this interaction? To what extent MARDI's researchers utilize their networks with farmers in their innovation? Do they codeliver innovation as suggested in social innovation? In order to form a more comprehensive analysis on the

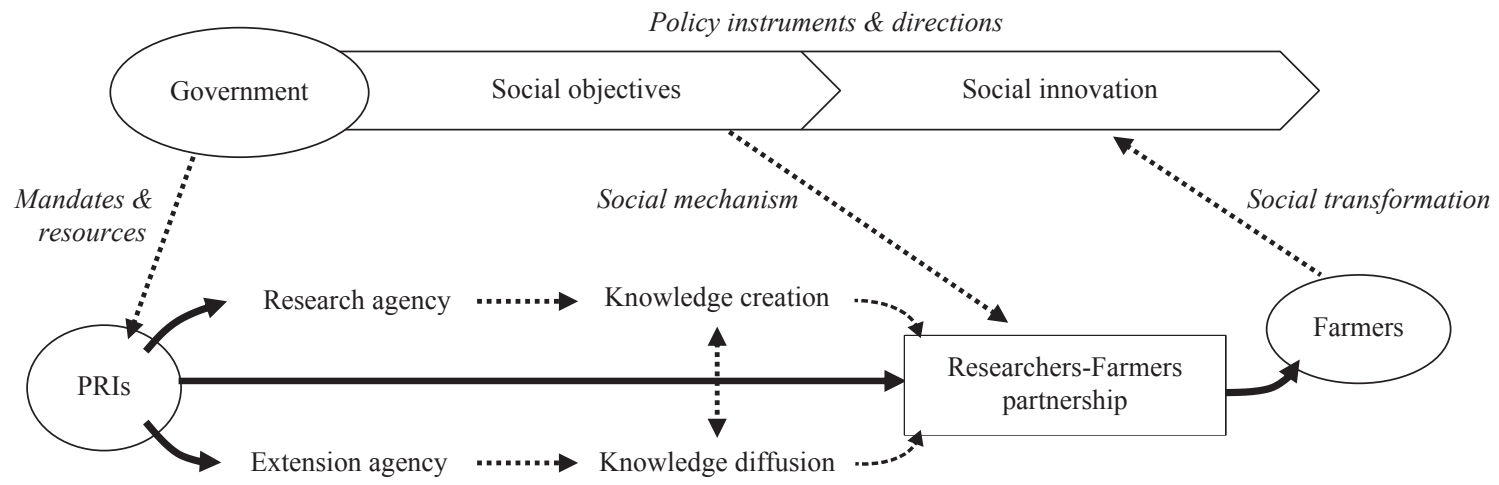

Figure 1. Conceptual framework. 
social innovation, our interviews cover other extension service agencies such as Department of Agriculture (DoA) at the district level, civil society organizations (CSOs), and officers from the main rice granary areas in Malaysia such as Muda Agricultural Development Authority (MADA) in the state of Kedah, and Sungai Panjang that is located at Integrated Agricultural Development Area-Barat Laut Selangor (IADA-B.L.S) in the state of Selangor.

\subsection{Data collection, analysis and interpretation}

The on-site interviews covered two main functions of MARDI, i.e. the research division and service division. The two criteria in selecting departments or divisions for interviews are: (a) the department that deals with end-user in any of their programs; and (b) they are managing or producing rice-paddy variety and its implementation. The respondents selected are actors that involve in: (a) the production and distribution of the rice varieties; (b) the production and selling of rice in the market; and (c) implementation and regulation of any MARDI's rice varieties.

A total of 30 interview sessions have been conducted during the period of May 2018 until early November 2018. For MARDI, the interview sessions have successfully covered the centers that are related to rice-paddy industry in Malaysia, namely: (1) Rice and Paddy Research Center; (2) Engineering Research Center; (3) Economics and Social Science Research Center; (4) Technical Service And Technology Commercialization Center; and (5) Promotion and Business Development Center. Several officers from the DoA - a key agriculture extension agency of the Ministry of Agriculture and Agro-based Industry (MoA) also had been interviewed. The selected farmers for the interviews were from two main rice granary areas in Malaysia, i.e. Kodiang that is located at MADA in the state of Kedah, and Sungai Panjang that is located at IADA-B.L.S. The interview protocols suggested by Yin (2003) were followed strictly. The interviews were recorded with permission and the interviewees will be referred for any unclear explanation during the interview process. More importantly, the interviewees were ensured that their identities will not be disclosed, and all data and information collected will be presented in an aggregated form. The study also consulted MARDI's top management on the findings and data validation. Other than that, any unclear interpretation of the data will be validated by the respondents to avoid misinterpretation and overgeneralization. Table 1 states the list of the interviewees who participated in this study.

\section{Data and findings}

\subsection{Public research institutions in Malaysia and MARDI}

In Malaysia, PRIs were established to investigate public problems in key areas such as agriculture, health and manufacturing. In this context, PRIs are expected to translate their research outcomes into applications that can help to rectify societal problems (Strong et al., 2018). Table 2 lists the main PRIs in Malaysia and their year of establishment. Several PRIs such as Institute of Medical Research, Malaysian Rubber Board, Forest Research Institute of Malaysia and Veterinary Research Institute are the pioneer PRIs in Malaysia which have been established before Malaysia obtained its independence in 1957. In general, PRIs have a clearly targeted user industry and their research mostly revolves around problem-solving and developing technologies that are sectoral and industry specific (Alavi and Azmi, 2013). However, PRIs' contribution to industrial development and creating domestic capabilities has been limited. This is mainly due to the lack of relevance between research undertaken by PRIs and the actual demand of the industry, as well as low level of awareness among the industry on the availability of support facilities in PRIs (Alavi and Azmi, 2013). The research process in PRIs is still adopting a linear approach with limited participation of endusers. Moreover, PRIs are constrained by civil service regulations from adopting more effective research management practices to enhance their research performances (Thiruchelvam, 2004).

MARDI was established in 1969 and it is regulated by the Laws of Malaysia (Act 11) MARDI Act 1969. The act entrusts MARDI to foster national agriculture development in R\&D of agricultural commodities 
Table 1. List of interviewees.

\begin{tabular}{|c|c|c|}
\hline Code & Expertise / roles & Profile \\
\hline R01 & Mechatronic engineering & Research officer for precision farming \\
\hline R02 & Agricultural business & Research officer for agribusiness and international trade \\
\hline R03 & Chemical engineering & Research officer for post-harvest technology and food processing \\
\hline R04 & $\begin{array}{l}\text { Technology transfer and } \\
\text { commercialization }\end{array}$ & Research officer for technology commercialization \\
\hline R05 & $\begin{array}{l}\text { Technology transfer and } \\
\text { commercialization }\end{array}$ & Research officer for technology commercialization \\
\hline R06 & Technology impacts and assessment & Research officer for technology commercialization \\
\hline R07 & $\begin{array}{l}\text { Technology transfer and } \\
\text { commercialization }\end{array}$ & Research officer for scale development \\
\hline R08 & $\begin{array}{l}\text { Technology transfer and } \\
\text { commercialization }\end{array}$ & Research officer for entrepreneur development \\
\hline R09 & Nanotechnology & Senior research officer for promotion and technology transfer \\
\hline R10 & Technology transfer & Research assistant in Tanjung Karang \\
\hline R11 & Plant breeding and genetics & Senior research officer for molecular breeding in Seberang Perai \\
\hline R12 & Electrical and electronic engineering & Research officer for precision farming in Seberang Perai \\
\hline R13 & Crop production & Research officer for agronomy in Seberang Perai \\
\hline R15 & Plant breeding and genetics & Policy maker in paddy and rice industry \\
\hline R16 & Agriculture & Extension service \\
\hline R17 & Agriculture & Extension service \\
\hline R18 & Farmer & $>10$ years in paddy farming and active in civil society organizations \\
\hline R19 & Farmer & A role model and a rice seeds cultivator. \\
\hline R20 & Farmer & $>20$ years in paddy farming and active in civil society organizations \\
\hline $\mathrm{R} 21$ & Farmer & $>30$ years in paddy farming and a farmer representative \\
\hline R22 & Farmer & $>40$ years in paddy farming \\
\hline $\mathrm{R} 23$ & Farmer & $>40$ years in paddy farming \\
\hline $\mathrm{R} 24$ & Farmer & $>30$ years in paddy farming and active in civil society organizations \\
\hline R25 & Farmer & A role model for farmers in Sg. Panjang \\
\hline R26 & Farmer & A role model for farmers in $S g$. Panjang \\
\hline $\mathrm{R} 27$ & Farmer & Inherits paddy fields from his family \\
\hline $\mathrm{R} 28$ & Farmer & Inherits paddy fields from his family \\
\hline R29 & Farmer & Inherits paddy fields from his family \\
\hline $\mathrm{R} 30$ & Worker in pesticide company & $>5$ years experiences in an international pesticide company \\
\hline
\end{tabular}

(except palm oil, rubber and cocoa), knowledge and skills sharing, consultancy, network development and research commercialization. MARDI operates under the purview of the MoA, and its operational structure can be generally divided into two divisions - research division and service division. In the case of rice-paddy industry, MARDI's roles encompass two broad national R\&D initiatives underlined by the MoA. Firstly, to perform quality research to increase the scientific knowledge and techniques in farming. Secondly, to disseminate research outcomes among farmers to increase the agricultural output.

MARDI's R\&D on rice varieties is led by researchers in the laboratory of Rice and Paddy Research Center. This is supported by other centers in the research division, namely Engineering Research Center focuses on the engineering development of farming mechanism; Biotechnology and Nanotechnology Research Center develops new breeds using hybrid technology and breeding; Economics and Social Science Research Center focuses on the socio-economic dimension of the industry. The main R\&D outcome is the improved rice varieties that will be cultivated into foundation seeds by gene bank and seed center. Besides, centers in service division are equally important in supporting the research divisions. For instances, Promotion and 
Table 2. List of public research institutions in Malaysia (NSRC, 2013).

\begin{tabular}{lll}
\hline Acronyms & Institutes & Year established \\
\hline IMR & Institute of Medical Research & 1901 \\
MRB & Malaysian Rubber Board & 1925 \\
FRIM & Forest Research Institute of Malaysia & 1929 \\
VRI & Veterinary Research Institute & 1948 \\
FRI & Fisheries Research Institute & 1957 \\
SIRIM & Standards and Industrial Research Institute of Malaysia & 1964 \\
MARDI & Malaysian Agricultural R\&D Institute & 1969 \\
NUKLEAR & Malaysian Nuclear Energy & 1972 \\
MPOB & Malaysian Palm Oil Board & 1977 \\
MIMOS & Malaysian Institute For Microelectronic Systems & 1985 \\
LKM & Malaysian Cocoa Board & 1988 \\
NAHRIM & National Hydraulic Research Institute of Malaysia & 1995 \\
STRIDE & Science and Technology Research Institute of Defense & 2002 \\
CREAM & Construction Research Institute of Malaysia & 2006 \\
\hline
\end{tabular}

Business Development Center emphases on promoting MARDI's research outcomes based on the principle public goods whereas Technical Service and Technology Commercialization Center assists in corporate business commercialization.

\subsection{Mother-and-baby trials: on-station research and on-farm experimentation}

Malaysia asserts Control of Paddy and Rice Act 1994 (Act 522) to regulate illegal possession on uncertified seedlings or rice. Only government appointed seed-producing companies are allowed to issue the certified seeds to the farmers. This is to ensure farmers only use genuine seeds and the seeds are not infected by dangerous diseases and pests (Ng et al., 2018). The protection towards the industry comprises of comprehensive standard operating procedures on the release of new rice varieties. The effort is attained by establishing an organized and efficient procedure in the process of breeding, evaluation, seed production and the registration of the rice varieties. The procedure also stresses on the need to involve the participation of farmers in the research on new varieties and breeding by gathering their feedbacks on the new varieties. More importantly, MARDI needs to ensure that the successfully registered seeds must be sufficient for distribution to the farmers.

R\&D on new rice varieties is led by the Rice and Paddy Research Center of MARDI and can be generally divided into two stages, i.e. on-station research and on-farm experimentation. The first stage of on-station research is carried out at the preliminary yield trials (PYT) stations. Several rice lines are selected for early evaluation for PYT. The trials were performed solely by researchers to ensure the uncertified breeds are not taken out from PYT station without permission. PYT will be conducted for two seasons to determine the selected rice lines in terms of its production capability and the nature of uniformity as a population. Based on the PYT results, the breeders (i.e. researchers) will recommend quality rice lines for advanced yield trials (AYT). At AYT stations, researchers will subsequently examine the characteristics of the rice lines in terms of yield production and stability. The rice lines will be going through screening processes on plant diseases and pests. Like PYT, in order to prevent seed leakage, visitors are not allowed to enter into the AYT trials box without being accompanied by the breeders. AYT is conducted for two seasons and the quality rice lines will be selected upon consensus by all the breeders for the first stage of on-farm experimentation - multilocation trials (MLT).

During MLT, researchers will examine the varieties' capability to survive on real paddy fields. This test will be performed on multiple granary areas and farmers' paddy plots will be rented as the trial plots. Only 
researchers will perform the test at this stage, whereas the farmers are not involved in any of the procedures. MLT plots will be monitored for three to four seasons before their physiological features are recorded. Besides to obtain the best varieties, MLT also functions as a platform for farmers to explore the new research from the PRI. Nevertheless, in order to avoid the leakages of varieties, the location chosen for the trial plots are not located at the areas that are easily accessible by the public.

After MLT, two or three best varieties will be chosen for local variety trials (LVT) in all the granaries in Malaysia for another two to four seasons. The major difference between MLT and LVT is the extent of farmers' involvement in the tests. MLT rents farmers' plots as a test plot without any involvement of the farmers; whereas LVT needs the farmers to conduct the test on their own plot. The chosen farmers will be given an agronomy package to help them to plant the new varieties. The objectives of LVT is to observe if the new rice varieties are suitable and adaptable by the farmers at their respective farms. Therefore, the selection for farmers that will conduct LVT will be based on their capabilities to oblige to the guidelines given by the PRI. LVT will be measured based on these conditions, i.e. yield, plant height, plant's resistance towards pest and disease. In fact, the involvement of farmers in LVT are indeed important as it is a compulsory condition for the varieties to be certified.

After the chosen varieties graduated from the on-farm research (both MLT and LVT), MARDI will conduct market research to gather consumers' feedback on the taste of the newly created rice. If the varieties are accepted, the breeder' seed will be given to Gene Bank to produce Foundation Seeds. The Foundation Seeds will be certified by Rice and Paddy Research Center. The endorsed Foundation Seeds will then be sold to seed producers' companies for them to produce Registered Seeds. These seed producers' companies are the government-appointed companies for the multiplication of seeds. DoA, an agriculture extension agency under the MoA, will certify the Registered Seeds. The Endorsed Registered seed will then be multiplied as Certified Seed and again, DoA will perform the certification through the Paddy Seedlings Verification Scheme - a scheme to certify the genetic purity and variety identification of the seeds. The farmers could buy the Certified Seeds for farming from these companies.

At the same time, the DoA also plays its roles in preparing observation plot to enable its officers to learn and observe the physiological needs of the seeds. The officers will produce a report as a feedback to MARDI's researchers. After the observation plot, DoA will perform promotion plot to attract farmers' interest in using the new Certified Seeds. Through DoA's promotion plots program, farmers receive support in the form of free seedlings for one hectare of paddy fields. Finally, the farmers will then sell their yields to the purchasing centers of Padiberas National Berhad (BERNAS) - a government-linked company, or to other private rice millers. The rice millers will process the harvested paddy and distribute the rice products to the market. The process of MARDI' involvement in Malaysia's rice-paddy industry is illustrated in Figure 2.

In short, there are two main observations that could be derived from our understanding on MARDI's roles in the rice-paddy industry value chain in Malaysia. Firstly, as a PRI, MARDI does not deal with or enter into the market directly to avoid any conflict of interests. MARDI keeps their roles in on-station research and on-farm experimentation. As a PRI, MARDI's research is for public goods - as part of the national social innovation agendas. Second, the only direct and formal platform for researchers to engage with farmers before the new variety reaches the target group is through the LVT. After that, the researchers only interact with farmers through workshops that were conducted by another extension agency, mainly the DoA.

\subsection{Impacts of rice-variety research}

Until 2018, MARDI has declared 49 rice varieties in which 36 of them are in white rice varieties. The success of R\&D in rice varieties is not only measured with the number of scientific findings generated, but they are being measured according to their capabilities to solve farmers' daily farming problems. By having rice varieties with higher potential yield and shorter maturation period, the farmers could reduce the production cost and increase their net profit. Figure 3 shows the potential yield and average maturation 


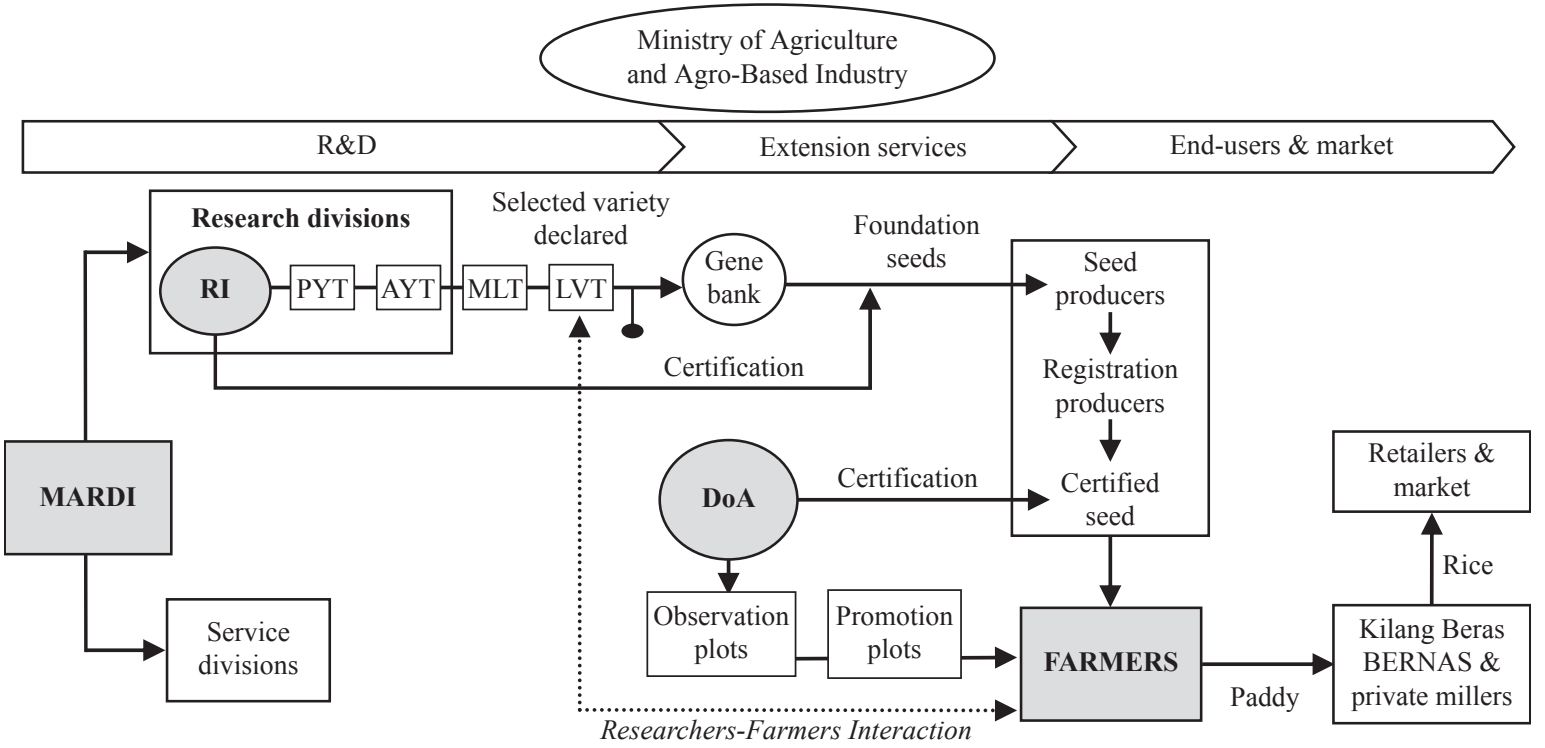

Figure 2. MARDI's rice varieties R\&D in Malaysia's rice-paddy industry.
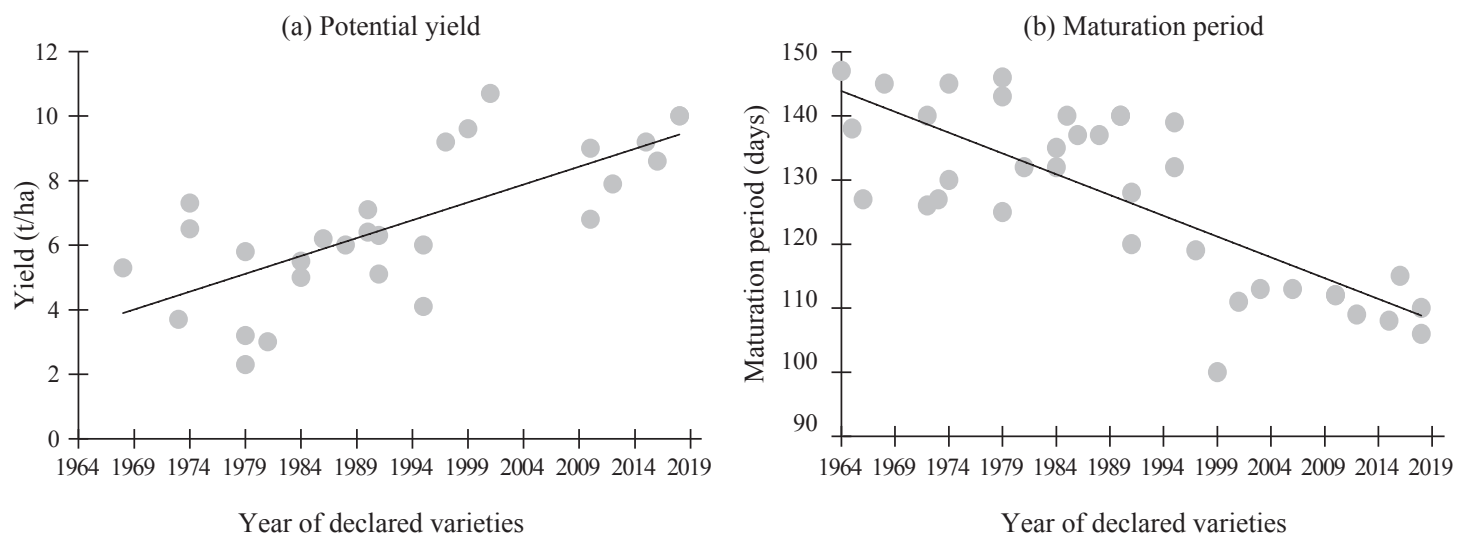

Figure 3. Potential yield and average maturation period of MARDI's white rice varieties. (each dot on the chart indicates a new variety introduced in the particular year)

period of new white rice varieties introduced by MARDI. Over the years, the new varieties introduced have shown an increase in the potential yield and it helps to improve farmers' income as well as contributing to the nation's economy. On the other hand, a faster maturation period is favored due to higher productivity of rice plantation by the farmers. It is important to note that besides producing rice varieties that are with higher potential yield and shorter maturation period, $R \& D$ on rice varieties also aim to increase the quality of rice in terms of its' resistance to diseases and pests.

At the same time, farmers are looking forward to the advancement of agricultural technology brought by the PRIs. For example, the latest rice varieties, MR220 CL1 and MR220 CL2 that were produced in MARDI's collaboration with a chemical company - BASF (Malaysia). The collaboration is able to combat weedy rice problem. The weedy rice is the main concern for the national agricultural sector. It has been the cause for BASF - a multinational corporation that focuses on the production of chemicals, to come out with the idea of weedy-rice-resistant variety. In order to do that, the company need to get direct access to the farmers and the only way it could be done was through a joint venture with MARDI - the only PRI that mandated to produce and declare rice varieties in the country. The productivity of the paddy farming has increased, and the problem of weedy rice has been elucidated. The high level of confidence of farmers on MARDI's 
research is indeed important for the technology adoption in the rice-paddy farming. The MARDI-BASF collaboration benefits both parties in which BASF got the access to the farmers and MARDI could retain its self-sustainability. This is a good example of public-private partnership in delivering public goods (i.e. social innovation) in the industry of agriculture.

\subsection{Forms of communication network and issues}

For both locations (i.e. Kodiang and Sungai Panjang), researchers have the chances to engage with farmers directly through workshops and seminars conducted by extension agencies such as the DoA, MADA and the district farmers organizations (PPK): 'In MADA, we have PPK that can gather farmers in their areas, and they will invite us (MARDI's officers) to give talks. From there we interact directly with the farmers. Whenever MARDI declared new varieties, they also will invite us to brief on the new varieties' (MARDI officer, July 31, 2018). During the engagement sessions, researchers explain their research and other information needed for the farmers to utilize the knowledge and technology. There is no other formal platform for the researchers to interact with farmers directly without going through any extension agencies, except during MARDI's exhibition. However, the engagement via exhibition is seemed 'one-off' and not in a sustainable form.

Even if there are issues like pests and diseases, the standard operating procedure explained that the farmers should make a report to DoA before the information reaches MARDI's researchers. The bureaucracy, however, tends to cause farmers to handle the issue themselves which sometimes could cause more damage (e.g. spread of plant disease and development of resistance towards pesticide). In some cases, farmers are able to find ways to engage with researchers via informal network. Often, 'some of the farmers also communicate directly with MARDI's researchers, especially in the research of pest and disease to inform their problems and seek for consultation, if they know the experts personally' (MARDI officer, July 31, 2018). In fact, farmers prefer to consult primary sources (i.e. scientific experts) about their issues in the paddy fields and have access to information as easy as possible without the hassle of bureaucracy and tedious procedure.

All interviewees acknowledge that researchers-farmers partnership is still vital to establish a more efficient and sustainable way to transfer knowledge and information and to ensure farmers follow the guidelines and recommendations given by the researchers. One of the researchers did mentioned that she 'hope to make all of her innovations (e.g. paddy machineries) to become public goods to benefit the farmers' (MARDI officer, May 22, 2018) and another researcher did mention that 'social innovation means the innovation that he produced is for the benefit of the farmers' (MARDI officer, July 30, 2018). Nonetheless, some of MARDI's researchers showed their concern towards direct engagement with farmers as it will cause redundancy with the current job scope of the existing extension agencies: 'We cannot deal directly with farmers. We have to use the extension agencies that we have, such as DoA, KADA and MADA. The role of these extension agencies is to transfer the knowledge and technology to the farmers. But sometimes because of the lack in resources (for extension agencies), MARDI also performs some of the extension services. There are some redundancies in term of SOP, but not in innovation' (MARDI officer, June 5, 2018). This concern is understandable as direct engagement between researchers and farmers could cause intellectual property issues (e.g. information leakage, release of unauthorized rice varieties, unethical and integrity issues, exploitation and manipulation of market).

A farmer kept repeating one phrase in most of his responses during our interview - '...the previous extension officers we used to work with were closer to the community in the village... The previous extension officers we used to work with were more knowledgeable...' (farmer, September 6, 2018). The strong ties between researchers, extension officers and farmers were used to be the norm in Malaysia's agricultural landscape during 1980s and 1990s. Extension officers were part of the community and became their personal consultants regarding to issues in paddy fields. However, nowadays the extension officers are burdened with heavy administrative tasks and this had reduced their consultation time with the farmers. 'Generation gap and lack of resources (i.e. numbers of officers) do exist in DoA. During 1980s, we have 'training and visit (2L) systems'. However, due to lack of staffs, there are redundancy in our job scope and more workload than before. Before this, about 
$70-80 \%$ of our job is $2 \mathrm{~L}$ and we have more hand-on workshops compared to now' (DoA officer, November 5, 2018). Besides, farmers are now much closer to social media and the internet. Often, they consulted their peers and shared their experiences about agricultural practices through the platform. For example, the biggest farmers' Facebook group, Padi Oh Padi is participated by more than 32 thousand farmers around the nation. Peer consultation has become the culture for Malaysian farmers to gain knowledge, build networks, share experience and even to consult on agricultural problems. However, based on our meeting with MARDI's researchers, this trend could be problematic as illegal market for unauthorized paddy seeds could happen without a proper monitoring from the authority.

\section{Discussion and policy directions}

\subsection{Revisiting researchers-farmers partnership}

Social relation transformation (e.g. community supportive) is needed to perform changes in governance system and organization (Moulaert, 2016). Also, the willingness to restructure existing social relationship to form collective social action are crucial for social change, thus solving societal problem (Cajaiba-Santana, 2014; Mumford, 2002). In this study, there are three actors that drive effective social innovation initiative - the PRI, agriculture extension agency and farmers. Such initiatives can be achieved if there are: (a) quality research by PRIs; (b) efficient extension agency in disseminating knowledge to the farmers; and (c) productive farmers in delivering high yields farming. Even though extension agencies, such as DoA in the context of this study, are the crucial pivot in ensuring the innovation reaches the target group, the presence of partnership between researchers in PRIs and farmers is as much as important. It serves as a platform for researchers to be aware of the farmers' constraint and there is a need for the farmers to receive first-hand knowledge in farming. Hence, the researchers could know the impacts of their research outcomes and farmers could appreciate the contributions of the scientific findings. These objectives are parallel to the concept of social innovation, which is meant to give positive impacts on the quality and quantity of life, to initiate novel solution that is more efficient to benefit the society rather than private individuals and to improve income and capabilities of stakeholders (Julie Caulier-Grice et al., 2012; Pol and Ville, 2009).

The scenario of related researchers-farmers partnership derived from the case study of MARDI is summarized in Figure 4. At the management and policymaking levels, the partnership between researchers and farmers will inform the management and decision makers the actual needs and constraints of the farmers on the ground. Consequently, the research programs to rectify these constraints can be better charted in accordance to the root cause of the problems. There is not much significant direct engagement between the researchers and farmers at the researchers' level - on-station research and on-farm experimentation. Even if there is little engagement in terms of on-farm referral of problems, it seems to have only benefits the selected resource-rich farmers who are more organized. We witnessed that the resource-rich farmers are the group of farmers that are commonly being selected and participated in the on-farm programs (i.e. MLT and LVT). Indeed, most of the farmers are seemed as passive recipients of the certified rice varieties through workshops and seminars, or some technology-transfer programs organized by the DoA. This is a typical transfer-of-technology model that focuses on resource-rich farmers; and often having difficulties to be translated or implemented into the resource-poor farmers. Nonetheless, it is observed that farmers are progressing towards more independence in term of their knowledge creation and information sharing. They are more 'tech-savvy' compared to the generation before them and the use of social media has accelerated the pace of knowledge dissemination and peer-learning amongst the farmers.

\subsection{Realizing social innovation through societal objectives, mechanism and transformation}

The conceptual framework of this study, as shown in Figure 1, suggests that public efforts to achieve social innovation are heavily driven by three fundamentals, namely clear societal objectives, effective social mechanism, and impactful social transformation. Societal objectives in social innovation puts social benefit before individual profit. Social mechanism encourages partnership and collaboration among stakeholders 


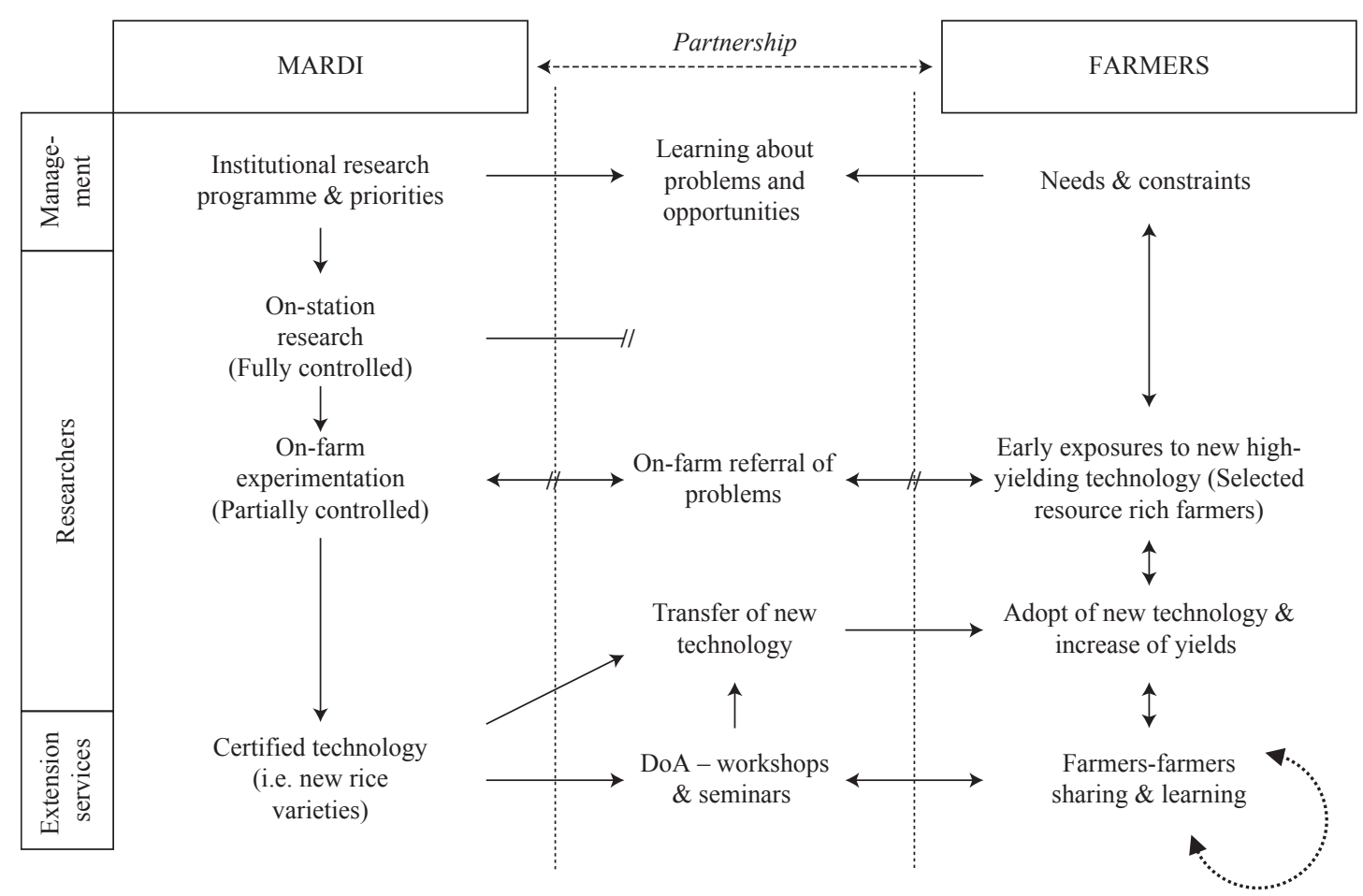

Figure 4. Activities in researchers-farmers partnership (modification from Chambers and Ghildyal, 1985).

in innovation process. Social transformation is the elevation of society from a passive end user into a more active participant in the process. Based on the case study of MARDI, we can summarize that:

- Societal objectives: It is important to define societal objectives according to specific societal context (Parra, 2013). Social innovation should portray the effort to fulfil the needs through its product and process. In this study, societal objective is achieved through the roles of a PRI in its rice varietal R\&D activity. The government has mandated the roles through the policy instruments and directions. There are several conclusions that could be drawn from MARDI's mandates, roles and performance, and from the case study of MR220 CL1 and MR220 CL2.

According to laws of Malaysia (Act 11) MARDI Act 1969, in which social objectives have been clearly regulated in the operation of MARDI, the mandates and roles of MARDI are ranged from scientific R\&D to dissemination of their research outcomes to the end-users. This includes providing extension services to entrepreneur in agri-business industry. In the year 1992, MARDI's job scope in commercialization was expanded. Nonetheless, the profit gained from the commercial activities are used to support MARDI's main mandate for R\&D but not for commercialization profits. In short, its main objective to serve societal needs is still preserved. The mandates are regulated via programs on rice varieties' R\&D. MARDI as the producer of innovation (i.e. rice varieties) gave impacts in increasing potential yield output and reducing maturation period for paddy plant, besides providing other solutions (e.g. meet market's need for specialty rice). Besides, MARDI's partnership with a private firm (i.e. BASF) to solve weedy rice problem and the MR219 and MR220 rice varieties that gave high rice yield to the farmers indicates public-private partnership as an alternative platform in sourcing firms' supports and technology in solving farming problems. In the case of weedy rice problem, MARDI acts as a bridging organization that connects private industry with the end user (i.e. farmers) through its public-private partnership with BASF.

- Social mechanism: Social innovation should address its fundamental concept of relationship, position and rules changes between the involved stakeholders, through unrestricted access of participation and collaboration (Voorberg et al., 2015). However, the research findings did not recognize any direct platform for researcher-farmer partnership without going through any extension agencies. Therefore, extension agencies in agricultural systems are vital in mediating PRI like MARDI with the end user. 
MARDI's intermediary roles in performing social mechanism of social innovation are limited through the current researcher-farmer partnership in the rice industry. In most cases, researchers are using the other existing extension services agencies to reach out to farmers. The co-production approach that suggests that farmers' participatory research is hardly to be achieved in this context. MARDI only performs the role as an information broker in disseminating information to increase knowledge and skills of the end user by interacting with the farmers through workshops. There is regulative restriction that discourages the direction engagement between researchers and farmers in rice variety R\&D. LVT and MLT phases in declaring new rice varieties are the only formal mediums that allow farmers to connect with MARDI's rice breeders. However, the selection of farmers that are involved in the trials should be taking poor-resource farmers into account. In addition, farmers prefer access to the primary source of the knowledge (i.e. the researchers). Farmers now are having more access to information through the internet and they demand for more updated information and advanced solutions to farming problems that are only able to be provided by scientists or researchers. In order to ensure every scientific discovery done by PRIs are well-delivered to the end user, extension agencies are required to have enough capacity and capability to deliver both scientific and know-how knowledge to the farmers.

- Social transformation: In a complex ecosystem like rice-paddy industry, PRIs alone could not sustain good adoption and implementation of innovation. Agricultural systems in Malaysia is depending on other innovation intermediaries (e.g. extension agencies and farmers' support groups) to transfer innovation and know-how knowledge, and also to define relevant societal need. Therefore, a good actor network is needed in agricultural system. CSOs and social media have the potential in assisting in that matter. Gallouj et al. (2018) highlighted that the involved stakeholders (especially the groups of end users) in social innovation should be empowered and have capability to get involved in the innovation process.

Based on the case study, Malaysian farmers have developed their own capacity to mobilize all types of resources (e.g. monetary, networking and human resource). They can be transformed from being a passive group of end users into a more active group of innovation actors. We observed that CSOs and social media had transformed Malaysian farmers' community. Peer consultation has become a culture among farming community in the country. This has changed the environment of the industry as farmers are becoming more active players in the sector. For instance, the communication gap between MARDI's researchers and farmers is due to the changes in farmers' preferences in primary source for knowledge. MARDI attempts to fill in the gaps by introducing mobile application (e.g. MyPadi) to allow more communication and social interaction between its researchers and end users.

Based on all the findings above, this paper suggests that the interaction and partnership among innovation actors (e.g. MARDI, extension agencies, firms, CSO and farmers) are crucial in developing a sustainable paddy-rice industry (Figure 5). Malaysia's agricultural system should provide a good ecosystem to allow more interaction among government agencies and between private entities. This includes to promote a more participatory approach in delivering rice variety to farmers. The agricultural policies should be directed to celebrate the competency of Malaysian farmers in knowledge generation and transfer. Farmers' groups and supporting CSOs should be empowered as they help the community to grow and improve.

\subsection{Refocusing on the context-specific issues of rice}

There are ample case studies to showcase the potential roles of government (and its research agencies) in developing agricultural sector. For instances, Iizuka and Gebreeyesus (2018) studied on government's roles in establishing a successful non-traditional agricultural export products such as cut flowers and blueberries; Thutupalli and Iizuka (2016) reveals the diverse pathways followed by local firms (i.e. in cotton industry) to catch-up; while Wong and Lim (2019) argued the productivity and innovation level of Taiwanese riceoriented agricultural production system. One of the similarities of these studies is their context of discussion is mainly on development of non-traditional agricultural export products and cash crop which underpinned with the concept of catch-up. They are about the firms' capability-building, market formation and globalization. Although the findings of these studies are useful and promising, the adoption of these findings to inform 


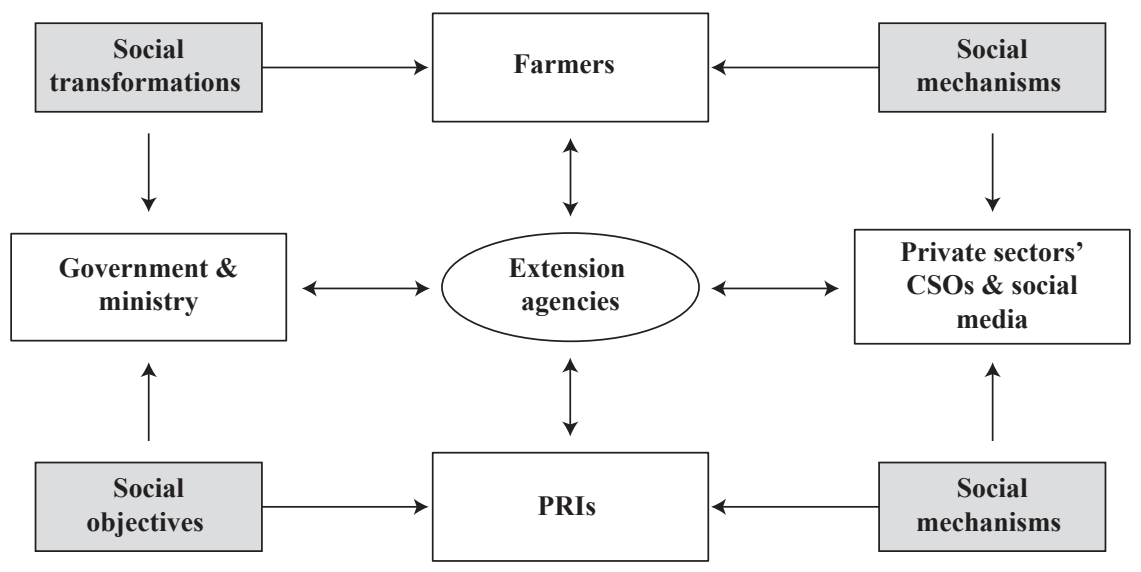

Figure 5. Sustainable social innovation framework for agriculture.

the policymaking process for paddy industry needs to be carefully scrutinized in order to avoid the risk of out of context interpretation.

This is based on the fact that rice production in developing countries - the case of Malaysia in this paper, is never being considered neither as a non-traditional agricultural export products nor cash crop (e.g. tropical fruits and vegetables). In fact, rice is a staple food and while the nation's self-sufficiency level of rice production is only about 70\% (Akhtar et al., 2019), we can understand why the Malaysian government sees the need to highly regulates the industry for the food security concern. Also, there is a difference in the context of development for firms (in catching-up strategy) and farmers (individuals and mostly villagers). Relatively, farmers are less competent in managerial, research, marketing and financial capabilities compared to firms. This is our study on researchers-farmers partnership towards the capability-building of knowledge dissemination and skill training, rather than discourse on market formation and globalization which is beyond the reach of the farmers in this context.

As rice industry is highly regulated from the control of seeds selection until market price, we observed that the researchers-farmers partnership is somehow not able to perform as expected. Our findings show that there are two scenarios in which researchers-farmers partnership occurs: (a) introduction and briefing on new technology or seed in which the engagement will be via extension agencies (e.g. DoA and PPK) since they are the on-site officers that understand the local problem. Extension agencies will invite MARDI to brief on seminars and workshops; and (b) 'troubleshooting' engagement for pest and disease in which agencies such as IADA, MADA and KADA are working together with agencies under the MoA including MARDI to solve farmers' on-farm problem. Even so, both engagements did shows indirect or informal communication between farmers and researchers, and it is important to note that for those who have the connection, initiative or knowledge will benefit better from this partnership. The one that do not have the capital will rely on the officer from DoA and PPK solely. Our findings also remind us the potential risk of having direct engagement because not all the knowledge and science should be transferred to all farmers. Targeted communication is more suitable and extension agencies could help in determining and assessing who is the target and how the communication should be. Nonetheless, one of the issues is having too many extension agencies involved in this communication network causes 'agency problem' such as overlapping of roles, inefficiency and bureaucratic. As a consequent, the farmers may seek for peer or online advice that contributes to malpractice.

\subsection{Policy directions}

This study proposed the following broad policy directions in promoting and sustaining public social innovation especially in the context of agriculture system: 
- Adopting active participatory approaches - PRIs could improve the current participatory approaches (e.g. improvement in LVT for researchers to introduce new varieties to farmers) to enhance community support in disseminating the outcomes of public R\&D. The new participatory approaches do not necessarily have to create new idea by acknowledging new local context, but it could be a better management of current local knowledge with a better integration with scientific knowledge. For example, PRIs could adopt 'mother-and-baby' trials which suits the concept of MLT and LVT. This approach requires researchers to test new varieties on-site (mother trial) and farmers could replicate the experiment according to their capacity and constraint (baby trials). The farmers are not only benefiting by observing the mother trial directly, but it also encourages them to engage with researchers to learn new techniques on the new varieties. At the same time, the researchers could understand and comprehend the constraints experienced by the farmers and improve their innovation to meet the needs. Participatory approaches also ensure that the partnership will include as many farmers as possible; the advanced large-scale farmers and small-scale farmers.

- Promoting and recognizing researchers-farmers partnership - PRIs should come out with an alternative to motivate their own researchers, especially the one who are willing to work directly with farmers. Research grant, achievement award, job promotion, media publicity and opportunities to grow in their career could make the best option for the incentives.

- Strengthening effective scientific communication skills - researchers in PRIs should acknowledge that scientific communication is crucial in delivering their innovation. Researchers should be able to convey scientific knowledge to farmers in layman words to be understood by the audience. Scientific communication workshops could be conducted to train researchers the social skills needed to promote their products. Even though the nature for PRIs is public goods, it is still important to deliver their products to attract the end users.

- Optimizing the use of social media - PRIs should make use of social media platform. Their current mobile applications for paddy, MyPerosakPadi could be improved and publicized, not only to the farmers but also to the public. Hence, a partnership between MARDI and media platform could assist in the effort. Indeed, the Quadruple Helix of Innovation Model that emphasizes on the synergy of four entities - government, universities, academia and civil society in forming a well-configured knowledge economy and society (Carayannis and Campbell, 2009) should be considered. The Quadruple Helix enlightens the co-existence and co-evolution of different knowledge and innovation paradigms and integrates the concept with a new element of media-based and culture-based public.

\section{Conclusions}

This study has examined researchers-farmers partnership in social innovation initiatives in the case of rice varietal research in Malaysia. It discovered the roles of PRIs in public social innovation and comprehended the transformation of social relations among stakeholders (e.g. farmers and researchers in agricultural sector). The findings exhibit that the 'mother and baby' trials, in which researchers improve on the ongoing experimentation together with farmers, can be used as a systematic mechanism for PRIs to play their roles in social innovation. The case of Malaysia, especially of MARDI, is a good example to inform the literature that researchers-farmers partnership at the stage of rice varietal R\&D is limited in which both parties are highly depending on other extension agencies for communication. This is mainly due to the fact that rice variety research is highly regulated for the purpose of maintaining food security of the nation. Such highly regulated research (as well as the market) is somehow different from other agro-based products. The study also found the potential of CSOs to transform farmers into more active innovation actors in agricultural innovation system. 


\section{Acknowledgements}

We would like to acknowledge the financial support provided by the Ministry of Higher Education Malaysia's Fundamental Research Grant Scheme (FRGS) (FP036-2016). We would like to thank MARDI, Department of Agriculture Malaysia and all the interviewees who have provided their valuable inputs during the interview sessions.

\section{Disclosure statement}

No potential conflict of interest was reported by the authors.

\section{References}

Adebayo, K., S.C. Babu, R. Sanusi and M. Sofola. 2015. Private sector participation in agricultural extension for cocoa farming in Nigeria: the case of multi-trex integrated foods. In: Y. Zhou and S.C. Babu (eds.) Knowledge driven development. Elsevier, New York, NY, USA, pp. 141-162.

Akhtar, R., M.M. Masud and R. Afroz. 2019. Perception of climate change and the adaptation strategies and capacities of the rice farmers in Kedah, Malaysia. Environment and Urbanization ASIA 10(1): 99-115.

Alavi, R. and I.M.A.G. Azmi. 2013. Public research, open science and innovation: creating the path for sustainable resource-led industrialisation in Malaysia. International Journal of Trade, Economics and Finance 4(3): 145.

Baxter, D., M. Schoeman, K. Goffin and P. Micheli. 2010. Public sector innovation: the role of commercial partnerships. Cranfield University, Bedfordshire, UK.

Bekkers, V., J. Edelenbos and B. Steijn. 2011. Linking innovation to the public sector: contexts, concepts and challenges. In: V. Bekkers, J. Edelenbos and B. Steijn (eds.) Innovation in the public sector: linking capacity and leadership. Palgrave Macmillan, Hampshire, UK, pp. 3-32.

Berthet, E.T., G.M. Hickey and L. Klerkx. 2018. Opening design and innovation processes in agriculture: insights from design and management sciences and future directions. Agricultural Systems 165: 111-115.

Beza, E., J. Steinke, J. Van Etten, P. Reidsma, C. Fadda, S. Mittra, P. Mathur and L. Kooistra. 2017. What are the prospects for citizen science in agriculture? Evidence from three continents on motivation and mobile telephone use of resource-poor farmers. PLOS ONE 12(5): e 0175700.

Bock, B.B. 2012. Social innovation and sustainability; how to disentangle the buzzword and its application in the field of agriculture and rural development. Studies in Agricultural Economics 114(2): 57-63.

Boon-Kwee, N., K. Thiruchelvam, W. Chan-Yuan and V. Chandran. 2016. Innovation for inclusive development in Southeast Asia: the roles of regional coordination mechanisms. The Pacific Review 29(4): 573-602.

Cajaiba-Santana, G. 2014. Social innovation: moving the field forward. A conceptual framework. Technological Forecasting and Social Change 82: 42-51.

Carayannis, E.G. and D.F. Campbell. 2009. Mode 3 and Quadruple Helix: toward a $21^{\text {st }}$ century fractal innovation ecosystem. International Journal of Technology Management 46(3-4): 201-234.

Caulier-Grice, J., A. Davies, R. Patrick and W. Norman. 2012. Defining social innovation. In: Social innovation overview: a deliverable of the project: the theoretical, empirical and policy foundations for building social innovation in Europe (TEPSIE): Young Foundation, European Commission, Brussels, Belgium.

Chambers, R. and B. Ghildyal. 1985. Agricultural research for resource-poor farmers: the farmer-first-andlast model. Agricultural Administration 20(1): 1-30.

Crawford, A., R. Nettle, M. Paine and C. Kabore. 2007. Farms and learning partnerships in farming systems projects: a response to the challenges of complexity in agricultural innovation. Journal of Agricultural Education and Extension 13(3): 191-207.

Denning, G. and F. Bernardo. 1995. Partnership in rice research: rationale, experience, and implications. GeoJournal 35(3): 374-383.

Gallouj, F., L. Rubalcaba, M. Toivonen and P. Windrum. 2018. Understanding social innovation in services industries. Industry and Innovation 25: 551-569. 
Harun, R., E.E.E. Ariff, S. Suhaimee, A.A. Sobri, B. Ahmad and F.H. Sufian. 2016. Economic assessment for inbred paddy in MADA and IADA Pulau Pinang. Economic and Technology Management Review 11: $127-141$.

Howells, J. 2006. Intermediation and the role of intermediaries in innovation. Research Policy 35(5): 715-728.

Iizuka, M. and M. Gebreeyesus. 2018. 'Discovery' of non-traditional agricultural exports in Latin America: diverging pathways through learning and innovation. Innovation and Development 8(1): 59-78.

Lauritzen, G.D. 2017. The role of innovation intermediaries in firm-innovation community collaboration: navigating the membership paradox. Journal of Product Innovation Management 34(3): 289-314.

Lember, V., T. Kalvet and R. Kattel. 2011. Public sector innovation at the urban level: the case of public procurement. In: V. Bekkers, J. Edelenbos and B. Steijn (eds.) Innovation in the public sector: linking capacity and leadership. Palgrave Macmillan, Hampshire, UK, pp. 82-104.

Lundvall, B.A. (ed.) 1992. National systems of innovation: towards a theory of innovation and interactive learning. Pinter Publishers, London, UK.

Mazzoleni, R. and R.R. Nelson. 2007. Public research institutions and economic catch-up. Research Policy 36(10): 1512-1528.

McKelvey, M. and O. Zaring. 2018. Co-delivery of social innovations: exploring the university's role in academic engagement with society. Industry and Innovation 25(6): 594-611.

Merrill-Sands, D. and M.-H. Collion. 1994. Farmers and researchers: the road to partnership. Agriculture and Human Values 11(2-3): 26-37.

Ministry of Agriculture and Agro-based Industry Malaysia. 2011. National agro-food policy 2011-2020. Ministry of Agriculture and Agro-based Industry Malaysia, Putrajaya, Malaysia.

Moulaert, F. 2016. Social innovation: institutionally embedded, territorially (re) produced. In: D. MacCallum and S.V. Haddock (eds.) Social innovation and territorial development. Routledge, London, UK, pp. 27-40.

Mulgan, G., S. Tucker, R. Ali and B. Sanders. 2007. Social innovation: what it is, why it matters and how it can be accelerated. Saïd Business School University of Oxford, Oxford, UK.

Mumford, M.D. 2002. Social innovation: ten cases from Benjamin Franklin. Creativity Research Journal 14(2): 253-266. https://doi.org/10.1207/S15326934CRJ1402_11

National Science Research Council Malaysia (NSRC). 2013. PRA performance evaluation: unlocking vast potentials, fast-tracking the future. UiTM Press, Shah Alam, Malaysia.

Ng, B.-K., C.-Y. Wong and A.S. Magli. 2018. Clusters innovation development in Malaysia. University Malaya Press, Kuala Lumpur, Malaysia.

Ngongoni, C.N., S. Grobbelaar and C. Schutte. 2017. The role of open innovation intermediaries in entrepreneurial ecosystems design. The South African Journal of Industrial Engineering 28(3). https://doi.org/10.7166/28-3-1839

O’Byrne, L., M. Miller, C. Douse, R. Venkatesh and N. Kapucu. 2014. Social innovation in the public sector: the case of Seoul metropolitan government. Journal of Economic and Social Studies 4(1): 51-69.

Organisation for Economic Cooperation and Development (OECD). 2011. Public research institutions: mapping sector trends. OECD Publishing, Paris, France. http://dx.doi.org/10.1787/9789264119505-en

Parra, C. 2013. Social sustainability: a competitive concept for social innovation? In: F. Moulaert, D. MacCallum, A. Mehmood and A. Hamdouch (eds.) The international handbook on social innovation: collective action, social learning and transdisciplinary research. Edward Elgar, Cheltenham, UK.

Phills, J.A., K. Deiglmeier and D.T. Miller. 2008. Rediscovering social innovation. Stanford Social Innovation Review 6(4): 34-43.

Pol, E. and S. Ville. 2009. Social innovation: buzz word or enduring term? The Journal of Socio-Economics 38(6): 878-885.

Short, J. and A. Kopp. 2005. Transport infrastructure: investment and planning. Policy and research aspects. Transport Policy 12(4): 360-367.

Snapp, S. 2002. Quantifying farmer evaluation of technologies: the mother and baby trial design. In: M.R. Bellon and J. Reeves (eds.) Quantitative analysis of data from participatory methods in plant breeding. CIMMYT, Mexico, DF, Mexico. 
Snapp, S., G. Kanyama-Phiri, B. Kamanga, R. Gilbert and K. Wellard. 2002. Farmer and researcher partnerships in Malawi: developing soil fertility technologies for the near-term and far-term. Experimental Agriculture 38(4): 411-431.

Strong, D.R., V. Chandran and C.S. Hayter. 2018. Great expectations: assessing the impact of commercializationfocused policies among Malaysia's public research institutes. Economics of Innovation and New Technology 27(5-6): 438-453.

Thiruchelvam, K. 2004. Towards a dynamic national system of innovation in Malaysia: enhancing the management of R\&D in public research institutions and universities. Asian Journal of Technology Innovation 12(2): 127-150.

Thutupalli, A. and M. Iizuka. 2016. Catching-up in agricultural innovation: the case of Bacillus thuringiensis cotton in India. Industrial and Corporate Change 25(6): 923-940. https://doi.org/10.1093/icc/dtv055

United Nations Development Programme (UNDP). 2014. Social innovation for public service excellence. UNDP Global Centre for Public Service Excellence, New York, NY, USA. Available at: https:// tinyurl.com/yd5z2fml

Voorberg, W.H., V.J. Bekkers and L.G. Tummers. 2015. A systematic review of co-creation and co-production: embarking on the social innovation journey. Public Management Review 17(9): 1333-1357.

Wong, C.Y. and G. Lim. 2019. A typology of agricultural production systems: capability building trajectories of three Asian economies. Asia Pacific Viewpoint 61(1): 37-53. https://doi.org/10.1111/apv.12220

Wu, M.C. 1995. Culture, social organisation and economic activities of a Chinese farming community: a case study in Sekinchan, Selangor, Malaysia. PhD-thesis, Institute of Higher Studies, University of Malaya, Kuala Lumpur.

Yang, H. and W.-S. Jung. 2016. Assessing knowledge structures for public research institutes. Journal of Contemporary Eastern Asia 15(1): 27-40.

Yin, R.K. 2003. Case study research: design and methods, $3^{\text {rd }}$ edition. Sage, Thousand Oaks, CA, USA. 
